\title{
Mental Wellbeing and Exercise Participation during COVID-19 Pandemic among Adult Residents of Nigeria's Niger Delta
}

\author{
Nabofa Ochuko Eric ${ }^{1, *}$, Akarah Emmanuel Oghenebrorien ${ }^{1}$, Angba Tessy Onogimesike ${ }^{2}$, \\ Onohwosafe Peter Suoke ${ }^{3}$
}

\author{
${ }^{1}$ Department of Human Kinetics, Recreation and Sports Science Education, Delta State University, Abraka, Nigeria \\ ${ }^{2}$ Department of Human Kinetics and Health Education, Faculty of Education, National Open University of Nigeria, University Village \\ Plot 91, Jabi, Abuja, Nigeria \\ ${ }^{3}$ Health and Safety Unit, Institute of Education, Delta State University, Abraka, Nigeria
}

Received October 19, 2020; Revised November 24, 2020; Accepted December 20, 2020

\section{Cite This Paper in the following Citation Styles}

(a): [1] Nabofa Ochuko Eric, Akarah Emmanuel Oghenebrorien, Angba Tessy Onogimesike, Onohwosafe Peter Suoke, "Mental Wellbeing and Exercise Participation during COVID-19 Pandemic among Adult Residents of Nigeria's Niger Delta," International Journal of Human Movement and Sports Sciences, Vol. 8, No. 6, pp. 534-542, 2020. DOI: 10.13189/saj.2020.080628.

(b): Nabofa Ochuko Eric, Akarah Emmanuel Oghenebrorien, Angba Tessy Onogimesike, Onohwosafe Peter Suoke (2020). Mental Wellbeing and Exercise Participation during COVID-19 Pandemic among Adult Residents of Nigeria's Niger Delta. International Journal of Human Movement and Sports Sciences, 8(6), 534-542. DOI: 10.13189/saj.2020.080628.

Copyright $\mathrm{C} 2020$ by authors, all rights reserved. Authors agree that this article remains permanently open access under the terms of the Creative Commons Attribution License 4.0 International License

\begin{abstract}
Exercise can help mitigate mental wellbeing problems that people are likely to suffer during the COVID-19 pandemic. Yet, there are few or no official guidelines on exercising among the strategies for containing the pandemic. It could be due to the fact that the relationship between exercise participation and mental wellbeing during the COVID-19 pandemic had been empirically demonstrated. This study was conducted to establish the relationship between exercise participation and mental wellbeing during the pandemic among the adult residents of Nigeria's Niger Delta metropolitan cities. The cross-sectional survey research design was adopted to study all adult residents in the area. A sample of 1,800 adult residents was selected using purposive and stratified systematic sampling techniques. The 5-item World Health Organization Well-Being Index (WHO-5) and the Exercise Participation Questionnaire (EPQ) adapted from the Historical Adulthood Physical Activity Questionnaire (HAPAQ) were the data collection instruments. Frequency counts, means, standard deviations and linear regression analysis were used to analyse data. It was found that, although Total Daily Energy Expenditure on exercise during the pandemic was found to be significantly $(\beta=0$.
\end{abstract}

$504, t=13.905, p=0.000)$ related to mental wellbeing of respondents during the pandemic. It was concluded that current exercise participation can help in preserving one's mental wellbeing during the COVID-19 pandemic.

Keywords Anxiety, Infections, Exercise Participation, Mental Wellbeing, Survey

\section{Introduction}

The Niger Delta region of Nigeria is the third largest wetland in the world [1]. Many people and companies are attracted to the area from all over the world because most of the oil exploration activities in Nigeria take place in the Niger Delta [2]. Therefore, the attendant heavy human presence and oil exploration activities in the area could be predisposing residents to high levels of living stress. Meanwhile, it has since been demonstrated that high levels of stress of living in any given area can increase the psychological costs of coping with life up to the extent that residents would develop serious stress leading to 
serious mental disorders [3].

The emergence of the dreaded new coronavirus disease (COVID-19) in the area on March, 27, 2020 [4] has caused and is still causing generalized fear and fear-induced behaviours among the populace. A generalized fear and fear-induced behaviour of this nature can negatively impinge on the mental wellbeing of residents [5]. To worsen this fear is the large-scale quarantine measure being put in place in every major city (City Lockdown) that confines residents to their homes [6]. The chances, therefore, are that the COVID-19 outbreak in the Niger Delta Area of Nigeria could have increased the stress of living in the area up to the point where there is generalized low levels of mental wellbeing among its residents.

It has been suggested that the only way to cope with high levels of stress in a situation where it is not possible to avoid the stressor, is to raise one's stress vulnerability threshold through regular doses of moderate exercise [7]. It is because exercise or guided physical activity is a form of predictable stress that supplies a kind of vaccination against uncontrolled stress that leads to mental disorders [8]. It has also been found that exercise mitigated negative effects of stress during prolonged periods of isolation and confinement when on space travel [9]. It is therefore possible for regular doses of moderate exercise to make it easy for one to cope well with the type of stress following the fear of the COVID-19 pandemic and still retain high levels of mental wellbeing. Despite the well-established benefits of exercise, the World Health Organization's (WHO) strategic preparedness and response plan for COVID-19 did not specify any clear strategy to address the exercise needs of any kind [10].

The World Health Organisation's(WHO, 2020a,b) $[11,12]$ recommendations on maintaining active lifestyles specify that adults with current health problems should: (i) climb stairs as much as possible; (ii) increase household chores; (iii) participate in online physical activity classes coupled with enjoyable music; (iv) perform muscle strengthening exercises; and (v) perform enjoyable physical activity. It needs to be noted that these recommendations are for adults with current health problems and not for the general adult population. Yet it is the general adult population that is likely to suffer from mental wellbeing disorders in the efforts to cope with the generalized fear and fear-induced behaviour associated with the COVID-19 pandemic. It is, therefore, not out of place to declare that there is little or no guideline for the public as to what people can or should do in terms of daily exercise or physical activity routines for maintaining mental wellbeing while coping with the stress of living in cities that are locked down during the pandemic [13].

The reason for this lack of clear guidance on exercising during the COVID-19 pandemic could be because no relationship between exercise participation and mental wellbeing during the COVID-19 pandemic had been empirically demonstrated. This study was therefore conducted to examine the relationship between self-reported exercise participation and mental wellbeing of adults residing in cities that were locked down in Nigeria's Delta region during the pandemic.

\section{Materials and Methods}

\subsection{Population of the Study}

The population of the study was made up of all adult male and female residents of the Niger Delta region of Nigeria. The nine (9) states comprising the Niger Delta region of Nigeria have a total of registered 18,868,810 voters distributed per state as follows: Abia $=1,932,892$; Akwa Ibom $=2,119,727$; Bayelsa $=923,182$; Cross River $=1,527,289$; Delta, 2,845,274; Edo, 2,210,534; Imo, 2,272,293; Ondo, 1,822,346 and Rivers, 3,215,273 [14]. Where current population census data are not available, the adult population may be estimated from existing official figures of registered voters in given communities, districts, or voting blocks [15]. The national census data [16] obtained in 2006, which comprise both children and adults, are the most recent ones in Nigeria. Since the 2006 census data can be considered as obsolete, and the fact that every reasonable adult would have registered as a voter in the last general elections in the country, the 2019 list of registered voters [14] was used to estimate the target population for this study to be $18,868,810$ male and female adults.

\subsection{Sample and Sampling Technique}

Three metropolitan cities, Port Harcourt in Rivers State, Uyo in Akwa Ibom State and Warri in Delta State were purposively selected for this study based on the fact that they were the ones locked down in the region as soon as the first death due to COVID-19 in Nigeria was announced on March, 27, 2020 [4]. There are three (3) residential areas in Uyo with a total of 76,758 registered voters; 22 residential areas with 337,941 registered voters in the Uvwie and Warri South Local Government Areas (LGAs) that make up Warri city; and 39 residential areas with 1,097,565 registered voters in Obio-Akpor and Port Harcourt LGAs that make up Port Harcourt city [14]. The stratified systematic sampling technique was used to select the desired sample from each of the residential areas in each metropolitan city as shown in Table 1 in line with the recommendations of the Centre for Disease Control and Prevention (CDC) [15]. 
Table 1. Study Sample Size Computation

\begin{tabular}{ccccc}
\hline City & $\begin{array}{c}\text { Total no of Residential } \\
\text { Areas }\end{array}$ & $\begin{array}{c}\text { Mean Population / } \\
\text { Residential Area }\end{array}$ & $\begin{array}{c}\text { Sample/Residential } \\
\text { Area }\end{array}$ & Total Sample/City \\
\hline Port Harcourt & 39 & 28,143 & $10(+50 \%=15)$ & $390(+50 \%=585)$ \\
Uyo & 3 & 25,586 & $128(+50 \%=192)$ & $384(+50 \%=576)$ \\
Warri & 22 & 15,361 & $18(+50 \%=27)$ & $396(+50 \%=594)$ \\
Total & 64 & 69,090 & $156(+50 \%=234)$ & $1170(+50 \%=1,755)$ \\
\hline
\end{tabular}

The overall sample size and sample sizes for each of the cities were computed using Epi Info ${ }^{\mathrm{TM}} 7$ Version 3 of $3 / 21 / 2016$. In accordance with the recommendations of the CDC [15], 50\% was added to this computed appropriate sample size, to cater for shortfalls in sampling, which are expected to accompany online questionnaires.

\subsection{Research Instruments}

Two research survey instruments were used for this study, the 5-item World Health Organization Well-Being Index (WHO-5) and the Exercise Participation Questionnaire (EHQ). The WHO-5 was used to measure mental wellbeing during the COVID-19 pandemic in the study area. The WHO-5 consists of five (5) simple and non-invasive questions, which tap into the subjective wellbeing of the respondents. Its scoring principle is based on a raw score ranging from 0 to 25 that is multiplied by 4 to give the final score that ranges from 0 representing the worst imaginable wellbeing to 100 representing the best imaginable wellbeing [17]. The WHO-5 is among the most widely used questionnaires for assessing subjective mental wellbeing. A systematic review of the WHO-5 established that it is a highly useful, reliable and valid tool that can be applied in research studies for assessing wellbeing in cross-sectional surveys [18]. The WHO-5 is therefore considered to have adequate reliability and validity for this study.

The EPQ is adapted from the Historical Adulthood Physical Activity Questionnaire (HAPAQ). The HAPAQ is designed to collect data regarding total adulthood physical activity at home, work and exercise found in competitive sport and casual exercises undertaken from the onset of adulthood to participants' current age [19]. The EPQ was used to collect data regarding only participation in exercise found in competitive sports during the pandemic. The EPQ has a set of identical questions that have to do with the intensity, frequency and duration with regards to the different types of exercises that were performed during the pandemic. In this manner, the EPQ was used to collect participants' self-reported cumulative exercise energy expenditure (CEEE) during the pandemic.

The guide provided by the Adult Compendium of Physical Activities [20] was used to assign intensity values, in metabolic equivalents (METs), for each reported exercise type. In accordance with standard practice, an exercise energy expenditure (EEE) score for a type of exercise reported to have been performed was computed by subtracting 1 MET, which represented resting metabolic rate, from the assigned intensity value, in MET, and then multiplied by the reported exercise duration [21]. The following equation [19] was then used to compute self-reported exercise energy expenditure (EEE) in $\mathrm{kJ} / \mathrm{min}$ :

$\sum\{(\mathrm{Ai}-1) \times 3.5 \times 20.3\} \times \mathrm{d}$. where $\mathrm{Ai}=$ Assigned Intensity, $\mathrm{d}=$ total duration (in hours) spent on exercise during the pandemic.

The EPQ is composed of the same HAPAQ items that measure total adulthood physical activity found in competitive sport and casual exercises undertaken from the onset of adulthood to participants' current age. The EPQ items have been indirectly validated against fitness, fatness, treadmill performance and high-density lipoprotein cholesterol (HDL-C) [21-23]. It was also found that the items in the section of the HAPAQ used to formulate the EPQ have broad scopes, and have low cost of administration while maintaining high levels of reliability [23]. The EPQ was therefore considered to have adequate validity and reliability for this study.

\subsection{Data Collection}

The telephone numbers of the Chairmen of the Landlords Associations of all the 64 residential areas in the study area were obtained from the Information Officers of the relevant LGAs. These Chairmen supplied the telephone numbers of their members. The WHO-5 and EPQ were converted to online forms with the aid of Google Forms and sent to the registered landlords that could be reached in the study area via the social media platform, WhatsApp. Each of the landlords, who agreed to participate in the study, was asked to help recruit their tenants to participate in the study as well. In all, out of the 1,800 copies of the questionnaires sent out online to the landlords, 1,190 were completely filled. This figure represented a $67 \%$ return rate, which did not fall below the computed minimum sample size of 1,170 .

\subsection{Data Analysis}

Frequency counts and percentages were used to analyse demographic data and scores of the studied variables of all 
the participants. Linear regression analysis was conducted to determine the association between exercise participation and mental wellbeing scores of the participants. Multiple regression analyses were conducted to examine the independent associations of religious affiliation, city of residence, sex, age, education and nature of employment with mental wellbeing and energy expenditure on exercise during the pandemic. All analyses were done with the aid of the Statistical Package for the
Social Sciences (SPSS [Version 22.0; IBM Corp]).

\section{Results}

On Table 2 are shown the demographic characteristics of the respondents.

Table 2. Respondents' Demographic Characteristics

\begin{tabular}{|c|c|c|c|c|}
\hline \multicolumn{2}{|c|}{ Demographic Variable } & \multirow{2}{*}{$\begin{array}{c}\text { Frequency } \\
398\end{array}$} & \multirow{2}{*}{$\begin{array}{c}\text { Percent } \\
33.4\end{array}$} & \multirow{2}{*}{$\frac{\text { Cumulative Percent }}{33.4}$} \\
\hline & Port Harcourt & & & \\
\hline City of Residence & Uyo & 397 & 33.4 & 66.8 \\
\hline \multirow{3}{*}{ Sex } & Warri & 395 & 33.2 & 100.0 \\
\hline & Male & 682 & 57.3 & 57.3 \\
\hline & Female & 508 & 42.7 & 100.0 \\
\hline \multirow{10}{*}{ Age Group } & Below 21 Years Old & 94 & 7.9 & 7.9 \\
\hline & $21-25$ Years Old & 215 & 18.1 & 26.0 \\
\hline & $26-30$ Years Old & 212 & 17.8 & 43.8 \\
\hline & $31-35$ Years Old & 176 & 14.8 & 58.6 \\
\hline & 36 - 40 Years Old & 129 & 10.8 & 69.4 \\
\hline & 41 - 45 Years Old & 108 & 9.1 & 78.5 \\
\hline & 46 - 50 Years Old & 87 & 7.3 & 85.8 \\
\hline & $51-55$ Years Old & 63 & 5.3 & 91.1 \\
\hline & $55-60$ Years Old & 62 & 5.2 & 96.3 \\
\hline & More than 60 Years Old & 44 & 3.7 & 100.0 \\
\hline \multirow{4}{*}{ Religious Affiliation } & Christianity & 1129 & 94.9 & 94.9 \\
\hline & Islam & 19 & 1.6 & 96.5 \\
\hline & $\begin{array}{c}\text { African Traditional } \\
\text { Religion }\end{array}$ & 18 & 1.5 & 98.0 \\
\hline & Others & 24 & 2.0 & 100.0 \\
\hline \multirow{6}{*}{ Education Level } & No Formal Schooling & 30 & 2.5 & 2.5 \\
\hline & Primary School & 105 & 8.8 & 11.3 \\
\hline & Secondary School & 228 & 19.2 & 30.5 \\
\hline & Diploma/NCE & 68 & 5.7 & 36.2 \\
\hline & First Degree & 451 & 37.9 & 74.1 \\
\hline & Postgraduate & 308 & 25.9 & 100.0 \\
\hline
\end{tabular}


On Table 3 is shown the distribution of the study participants according to their Mental Wellbeing Scores. The table shows that $42(3.53 \%)$ of the participants had the worst possible mental wellbeing score of 0.00 . It is also shown on table that a whole $610(51.26 \%)$ of all the participants had mental wellbeing scores that are less than 48 , a score that is considered as below the average wellbeing score of $50.00 \%$ [17].

Table 3. Total Wellbeing Scores according to City of Residence

\begin{tabular}{|c|c|c|c|c|c|c|}
\hline \multirow{2}{*}{ Total Wellbeing Score } & \multicolumn{3}{|c|}{ Frequency in City of Residence } & \multirow{2}{*}{ Total Frequency } & \multirow{2}{*}{$\begin{array}{l}\text { Percent of } \\
\text { Total }\end{array}$} & \multirow{2}{*}{$\begin{array}{c}\text { Cumulative Percent of } \\
\text { Total }\end{array}$} \\
\hline & Port Harcourt & Uyo & Warri & & & \\
\hline 0.00 & 30 & 6 & 6 & 42 & 3.53 & 3.53 \\
\hline 4.00 & 1 & 12 & 1 & 14 & 1.18 & 4.71 \\
\hline 5.00 & 1 & 0 & 0 & 1 & 0.08 & 4.79 \\
\hline 7.00 & 0 & 0 & 1 & 1 & 0.08 & 4.87 \\
\hline 8.00 & 5 & 5 & 5 & 15 & 1.26 & 6.14 \\
\hline 12.00 & 3 & 3 & 14 & 20 & 1.68 & 7.82 \\
\hline 16.00 & 1 & 13 & 1 & 15 & 1.26 & 9.08 \\
\hline 20.00 & 51 & 15 & 38 & 104 & 8.74 & 17.82 \\
\hline 24.00 & 10 & 34 & 22 & 66 & 5.55 & 23.36 \\
\hline 28.00 & 10 & 23 & 22 & 55 & 4.62 & 27.98 \\
\hline 32.00 & 8 & 31 & 42 & 81 & 6.81 & 34.79 \\
\hline 36.00 & 10 & 22 & 10 & 42 & 3.53 & 38.32 \\
\hline 40.00 & 46 & 11 & 23 & 80 & 6.72 & 45.04 \\
\hline 44.00 & 12 & 25 & 13 & 50 & 4.20 & 49.24 \\
\hline 48.00 & 8 & 8 & 8 & 24 & 2.02 & 51.26 \\
\hline 52.00 & 10 & 10 & 10 & 30 & 2.52 & 53.78 \\
\hline 56.00 & 16 & 16 & 16 & 48 & 4.03 & 57.82 \\
\hline 60.00 & 31 & 20 & 20 & 71 & 5.97 & 63.78 \\
\hline 64.00 & 15 & 15 & 15 & 45 & 3.78 & 67.56 \\
\hline 68.00 & 22 & 22 & 21 & 65 & 5.46 & 73.03 \\
\hline 72.00 & 17 & 17 & 17 & 51 & 4.29 & 77.31 \\
\hline 76.00 & 20 & 19 & 20 & 59 & 4.96 & 82.27 \\
\hline 80.00 & 26 & 26 & 25 & 77 & 6.47 & 88.74 \\
\hline 84.00 & 13 & 13 & 13 & 39 & 3.28 & 92.02 \\
\hline 88.00 & 8 & 8 & 8 & 24 & 2.02 & 94.03 \\
\hline 92.00 & 6 & 6 & 6 & 18 & 1.51 & 95.55 \\
\hline 96.00 & 6 & 5 & 6 & 17 & 1.43 & 96.98 \\
\hline 100.00 & 12 & 12 & 12 & 36 & 3.03 & 100.00 \\
\hline Total & 398 & 397 & 395 & 1190 & 100.00 & \\
\hline
\end{tabular}

Table 4. Distribution of Respondents according to their Exercise Participation Scores

\begin{tabular}{ccccccc}
\hline $\begin{array}{c}\text { Types and Intensities of Exercises Participated in during } \\
\text { the Pandemic }\end{array}$ & \multicolumn{2}{c}{ Frequency in City of Residence } & \multirow{2}{*}{ Frequency } & Percent \\
\cline { 2 - 4 } None & Port Harcourt & Uyo & Warri & & & 51.8 \\
Calisthenics (e.g., push-ups, sit-ups, pull-ups, jumping & 205 & 206 & 206 & 617 & 1.6 \\
$\begin{array}{c}\text { jacks), vigorous effort (8.0) } \\
\text { Soccer, casual, general (7.0) }\end{array}$ & 18 & 0 & 1 & 19 & 15.3 \\
Calisthenics (e.g., sit-ups, abdominal crunches), light effort & 39 & 67 & 76 & 182 & 31.3 \\
(2.8) & 136 & 124 & 112 & 372 & $\mathbf{3 9 5}$ & $\mathbf{1 0 0 . 0}$ \\
\hline
\end{tabular}


On Table 4 is shown the distribution of respondents according to their exercise participation scores. The types of competitive sport or casual exercises performed, with assigned intensity values in METs within brackets, are shown on the table. The table shows that the adult residents of the Niger Delta region of Nigeria participated in only two (2) main types of exercises, Calisthenics (vigorous or light effort) and casual or general soccer during the lockdown.

Table 5. Descriptive Statistics of the Studied Variables among those who Exercised during the Pandemic Lockdown

\begin{tabular}{cccc}
\hline Variables & Mean & Std. Deviation & N \\
\hline $\begin{array}{c}\text { Total Wellbeing Score } \\
\text { Total Daily Energy Expenditure } \\
(\mathrm{KJ} / \mathrm{d})\end{array}$ & 42.01 & 26.18 & 573 \\
\hline
\end{tabular}

On Table 5 are summarised the scores of the study dependent and independent variables. The table shows that the adult residents in the study area had a mean wellbeing score of $42.01(\mathrm{Std} \operatorname{Dev}=26.18)$, a score that is lower than the average wellbeing score of 50.00 and total daily energy expenditure score of $231,539.28 \mathrm{KJ} / \mathrm{d}$ (Std Dev $=48.91$ ).

On Table 6 are shown the results of the linear regression analysis with a computed $\mathrm{R}$ Square value of 0.254 . The change statistics shown on the table $\left(\mathrm{F}_{1,571}=\right.$ 194.608, $\mathrm{p}=0.000$ ) indicate that the participants significantly differed in mental wellbeing scores according their energy expenditure on exercise during the pandemic. On the table are also shown the coefficients $(\beta$ $=0.504, \mathrm{t}=13.950, \mathrm{p}=0.000)$ which suggest that the significant difference in mental wellbeing found among the participants was significantly due to their daily exercise energy expenditure as a result of participation in exercise during the pandemic.

The between subject effects of the participants who exercised during the pandemic did not vary significantly according to religious affiliation $\left(\mathrm{F}_{3}=1.789, \mathrm{p}=0.147\right)$ in mental wellbeing and $\left(F_{3}=1.783, p=0.149\right)$ in energy expenditure on exercise. While the participants who exercised did not vary significantly according to city of residence in their mental wellbeing $\left(\mathrm{F}_{2}=0.031, \mathrm{p}=0.969\right)$, they varied significantly $\left(\mathrm{F}_{2}=17.453, \mathrm{p}=0.000\right)$ in their energy expenditure on exercise. Although, the participants who exercised did not vary significantly according to sex in their mental wellbeing $\left(\mathrm{F}_{1}=0.386, \mathrm{p}=0.534\right)$, they varied significantly $\left(F_{1}=6.399, p=0.012\right)$ in their energy expenditure on exercise. The between subjects effects of participants who exercised during the pandemic were found to significantly vary in their mental wellbeing and energy expenditure on exercise respectively according to age $\left(\mathrm{F}_{9}=10.612, \mathrm{p}=0.000\right)$ and $\left(\mathrm{F}_{9}=3.304, \mathrm{p}=0.001\right)$; education level $\left(\mathrm{F}_{5}=44.170, \mathrm{p}=0.000\right)$ and $\left(\mathrm{F}_{5}=7.920, \mathrm{p}\right.$ $=0.000)$; and nature of employment $\left(\mathrm{F}_{36}=3.225, \mathrm{p}=\right.$ $0.000)$ and $\left(\mathrm{F}_{36}=4.377, \mathrm{p}=0.000\right)$.

\section{Discussion}

This study was conducted to examine the relationship between exercise participation and mental wellbeing among adult residents of Nigeria's Niger Delta Region during the pandemic. It was observed that majority of the participants, $617(51.8 \%)$, in the studied three metropolitan cities, did not engage in any kind of competitive sport or casual exercise since the beginning of the COVID-19 pandemic. It was therefore expected that the stress vulnerability threshold would be very low among residents in the study area with high levels of stress and attendant low levels of mental wellbeing scores [7]. This assertion got support in the findings, shown on Table 3 that most of the studied adult residents of the Niger Delta region of Nigeria, 610 (51.26\%), had mean mental wellbeing score that is below 48 , a score considered as being below the average wellbeing score of $50.00 \%$ [17]. It is because a reasonable number of the respondents, 42 $(3.53 \%)$, were found to have had the worst possible mental wellbeing score of 0.00 .

Table 6. Influence of Daily Energy Expenditure due to Exercise on Wellbeing during the Pandemic

\begin{tabular}{cccccccc}
\hline & \multicolumn{4}{c}{ Change Statistics } & \multicolumn{3}{c}{ Coefficients } \\
\hline R Square & F Change & df1 & df2 & Sig. F Change & Beta & T & Sig \\
0.254 & 194.608 & 1 & 571 & 0.000 & 0.504 & 13.950 & 0.000 \\
\hline
\end{tabular}

Dependent Variable: Total Mental Wellbeing Score

Independent Variable: Total Daily Energy Expenditure on Exercise 
It has been demonstrated, on Table 6, that exercise participation, measured as daily energy expenditure on exercise during the pandemic had a significant $(\beta=0.504$, $\mathrm{t}=13.950, \mathrm{p}=0.000)$ influences on mental wellbeing during the COVID-19 pandemic among adult residents of the Niger Delta area of Nigeria. The implication is that exercise participation could have the potential to protect adults against mental wellbeing problems associated with the pandemic. This finding could be said to be in agreement with previous researches which demonstrated that fitter astronauts were better able to cope with the stress of isolation and confinement with which astronauts are faced during flight [9].

The result of this study that the participants who exercised did not vary significantly according to sex in their mental wellbeing appears contradict previous findings that showed a significant influence of each of sex $\left(\chi^{2}=0.786 ; p<0.05\right)$ on psychological wellbeing of undergraduates in Nigeria [24]. This contradiction could be due to the fact that both male and female participants in this study were struggling to cope with the stress of surviving the COVID-19 Pandemic. It is therefore reasonable for both sexes to have mental wellbeing scores that do not differ significantly because they are equally faced with the stress of surviving the pandemic. Moreover, it has been demonstrated earlier on that there were not significant differences in both sexes of Africans who are equally stressed in a Mental Health Continuum [25].

Although this study has shown that sex did not affect mental health responses to the stress of living in metropolitan cities that were locked down, it was found that the study participants varied significantly $\left(\mathrm{F}_{1}=6.399\right.$, $\mathrm{p}=0.012)$ in their energy expenditure on exercise according to sex during the pandemic. This finding is consistent with previous researches which demonstrated that young female adults in Nigeria were more likely to be inactive and less likely to be moderately active [26]. Additionally, it found earlier on that people who were females were less likely to participate in sport because women were less likely to engage in vigorous physical activity [27].

Although, the participants who exercised did not vary significantly according to city of residence in their mental wellbeing $\left(F_{2}=0.031, p=0.969\right)$, they were found to vary significantly $\left(\mathrm{F}_{2}=17.453, \mathrm{p}=0.000\right)$ in their energy expenditure on exercise. The finding that the participants who exercised did not vary significantly according to city of residence in their mental wellbeing appears to be in conflict with the results of earlier studies among undergraduates [25]. This finding is not surprising given the fact that all metropolitan cities have similar characteristics and similar in their types of residents who are generally involved in oil exploration activities [2]. However, the other finding that the participants varied significantly in their energy expenditure on exercise during the pandemic implies that the city-wide lockdown during the pandemic allowed some kind of movement that made it possible to exercise in some of the cities than in others.

This study has also shown that mental wellbeing and energy expenditure on exercise, during the pandemic, were significantly influenced by age, education level and nature of employment. These findings are consistent with the results of previous researches [25-27]. The finding that mental wellbeing during the pandemic was influenced by age, education level and nature of employment could be seen as providing empirical support for postulations that socio-demographic variables could play a role in determining holistic psychological well-being among South African Setswana-speaking community residents [25]. Age, employment and education were equally found to be associated with higher psychological well-being.

Previous studies have established that people who were older were less likely to participate in sport, physical activity decreased with age, education and nature of employment [27]. It was for this reason that education, especially physical education, was recommended as a step towards making working adult to inculcate the habit of regularly participating in physical activities [28]. These findings could thus be seen as providing support for the results of this study that age, education and nature of employment were influential in energy expenditure on exercise during the pandemic lockdown.

The results of this study that the participants who exercised during the pandemic did not vary significantly according to religious affiliation in their mental wellbeing $\left(F_{3}=1.789, p=0.147\right)$ appears to contradict findings of earlier studies that religion is a major demographic correlate of mental health responses to stressful situations among the elderly [25]. It could therefore be deduced that religion may not be able to mitigate mental wellbeing responses to the pandemic in the study area. Although religion has been suggested to be among the socio-demographic determinants of physical activity among workers [28], this study has shown that energy expenditure on exercise did not vary significantly $\left(\mathrm{F}_{3}=\right.$ $1.783, \mathrm{p}=0.149$ ) according to religious affiliation. It could therefore be stated that religious affiliation did not influence exercise behaviour, reflected in the amount of energy expenditure, during the pandemic in the study area.

\section{Conclusions}

It was concluded that exercise participation, measured by daily energy expenditure through current participation in physical activity found in competitive sport and casual exercises, has the potential to directly influence the mental wellbeing of adult residents of the Niger Delta Region of Nigeria. Some demographic factors, such as age, education and nature of employment, were found to be capable of moderating the potential of exercise 
participation in influencing mental wellbeing during the pandemic. Other socio-demographic factors, including religious affiliation, city of residence and sex may not influence the extent to which exercise participation can ameliorate the mental wellbeing responses to the COVID-19 pandemic.

\section{Recommendations}

There is a need to give guidance on how to exercise regularly so as to enhance mental wellbeing for surviving the public measures being put in place to contain the COVID-19 pandemic. It is because regular participation in well-guided exercise can help raise people's stress vulnerability thresholds and so improve mental wellbeing among residents of the region during the pandemic. Age, education and nature of employment should therefore be taken into account when designing exercises for improving mental wellbeing during the pandemic. The type of exercise to be recommended in the guidelines on exercise during the COVID-19 pandemic should be such that increases current energy expenditure levels while observing the measures specified for containing the pandemic. The most common/preferred type of exercise in the region was found, in this study, to be the casual and general form of soccer. This form of soccer is a vigorous physical activity with an energy cost of 7.0 Mets, and can be played in open courtyards and informal fields around the home. It should thus be proper to recommend that male and female adult residents of the Niger Delta Region of Nigeria should exercise regularly by playing such sports as the casual and general form of soccer in their compounds and the informal field near their homes during the pandemic so as to increase their current energy expenditure levels.

The WHO's $[11,12]$ recommendations on maintaining active lifestyles could be adhered to by engaging in exercises that are not only indigenous to the residents of the Niger Delta Region of Nigeria, but also those activities that residents find to be very interesting and, which are capable of increasing daily energy expenditure of exercise while staying at home. It is therefore recommended that, while the pandemic lasts and people are locked down in their homes, they should make it their priority to exercise by participating in praise with dance or run and spiritual dancing within and around their homes every morning. It is an enjoyable and familiar exercise that is capable of eliciting 5.0 METs of energy expenditure, and so could help to maintain one's mental wellbeing during the pandemic. Jog/walk combination (jogging component of less than 10 minutes) and general rope skipping, are capable of eliciting 6.0 METs and 11.0 METs respectively. Participating in these exercises every evening could, therefore help inoculate one against the stress of coping with life in the Nigeria's Niger Delta Region during the COVID-19 pandemic.

\section{REFERENCES}

[1] Azaiki S, "Inequalities in Nigerian politics: the Niger Delta, resource control, underdevelopment and youth restiveness", Treasure Books, 2003, pp. 51-55.

[2] Nabofa OE, Onohwosafe SP, "The need for environmental epidemiological studies in the Niger Delta Area of Nigeria", Studies on Ethno-Medicine, vol. 3, no. 3, pp. 201-204, 2011. https://doi.org/10.1080/09735070.2011.11886409

[3] Bakker AB, Hakanen JJ, Demerouti E, Xanthopoulou D, "Job resources boost work engagement, particularly when job demands are high", Journal of Educational Psychology, vol. 99, no. 2, pp. 274-284, 2007.

[4] Nigeria Centre for Disease Control (NCDC). "National strategy to scale up access to coronavirus disease testing in Nigeria", covid19.ncdc.gov.ng > files > COVID19TestingStr ategy_Lz3ZVST (Accessed April 20, 2020).

[5] Dong L, Bouey J, "Public mental health crisis during COVID-19 pandemic, China", Emerging Infectious Diseases, vol. 26 no. 7, pp. 1616-1618, 2020.

[6] Brooks SK, Webster RK, Smith LE, Woodland L, Wessely S, Greenberg N, Rubin GJ, "The psychological impact of quarantine and how to reduce it: rapid review of the evidence", The Lancet Rapid Review, vol. 395, no. 10227, pp. 12-920, 2020.

[7] Muoboghare PA, Nabofa OE, Akarah E. "Stress management exercises for the competitive athlete: attaining millennium development goal number six", Journal of International Council for Health, Physical Education, Recreation, Sport and Dance African Region, The Official Publication of the International Council for Health, Physical Education, Recreation, Sport, and Dance (ICHPER.SD) African Region, vol. 1, no. 2, pp, 19 - 26, 2007.

[8] Nordqvist C, "What Is Mental Health? What Is Mental Disorder?", Medical News Today, http:/www.medicalnewst oday. com/articles/154543.ph, (Accessed June 18, 2009).

[9] Simpson RJ, "Exercise, Immunity and the COVID-19 Pandemic",

https://www.acsm.org/blog-detail/acsm-blog/2020/03/30/ex ercise-immunity-covid-19-pandemic, (Accessed April 30, 2020).

[10] World Health Organization, "WHO R\&D Blueprint: novel Coronavirus: outline of designs for experimental therapeutics",

https://apps.who.int/iris/handle/10665/330695, (Accessed April 30, 2020).

[11] World Health Organization, "Diet and physical activity factsheet for adults", https://www.who.int/dietphysicalactivi ty/factsheet_adults/en/(Accessed May 6, 2020).

[12] World Health Organization, "physical-activity", Newsroom, https://www.who/int/news-room/campaigns/connecting-the -world-to-combat-coronavirus/healthyathome/healthyathom e/physical-activity, (Accessed May 6, 2020).

[13] Chen P, Mao L, Nassis GP, Harmer P, Ainsworth BE, Li F. 
"Coronavirus disease (COVID-19): The need to maintain regular physical activity while taking precautions", Journal of Sport and Health Science, vol. 9, no. 2, pp. 103-104, 2020. https://doi.org/10.1016/j.jshs.2020.02.001.

[14] Independent National Electoral Commission (INEC). "Official directory of registered voters, Updated on January 24, 2019". www.placn.org>situation room>category >voter-r egistration. (Accessed April 30, 2020).

[15] Centers for Disease Control and Prevention (CDC), "A guide to conducting household surveys for Water Safety Plans. U. S. Department of Health and Human Services", www.cdc.gov. (Accessed April 26, 2020).

[16] National Population Commission, "National General Census Report", Abuja: Federal Republic of Nigeria, 2006.

[17] Topp CW, Østergaard SD, Søndergaard S, Bech P. "The WHO-5 Well-Being Index: a systematic review of the literature", Psychotherapy and Psychosomatics, vol. 84, no. 3, pp. 167-176, 2015. https://doi.org/10.1159/000376585.

[18] Hall T, Krahn GL, Horner-Johnson W, Lamb G, "Rehabilitation Research and Training Center Expert Panel on Health Measurement. Examining functional content in widely used Health-Related Quality of Life scales", Rehabilitation Psychology, vol. 56, no. 2, pp. 94-99, 2011. doi: 10.1037/a0023054. PMID: 21574727.

[19] Besson H, Harwood CA, Ekelund, U, Finucane FM, McDermott CJ, Shaw PJ, Wareham NJ, "Validation of the historical adulthood physical activity questionnaire (HAPAQ) against objective measurements of physical activity", International Journal of Behavioral Nutrition and Physical Activity vol. 7, n. 54, 2010. https://doi.org/10.118 6/1479-5868-7-54.

[20] Ainsworth BE, Haskell WL, Herrmann SD, Meckes N, Bassett Jr DR, Tudor-Locke C, Greer JL, Vezina J, Whitt-Glover MC, Leon AS, "Compendium of Physical Activities: a second update of codes and MET values", Medicine and Science in Sports and Exercise, vol. 43, no. 8, pp. 1575-1581，2011. DOI:10.1249/MSS.0b013e31821ece 12 .
[21] Winters-Hart CS, Brach JS, Storti KL, Trauth JM, Kriska $\mathrm{AM}$, "Validity of a questionnaire to assess historical physical activity in older women", Medicine and Science in Sports and Exercise, vol. 36, no. 12, pp. 2082-2087, 2004. doi: 10.1249/01.MSS.0000147592.20866.07.

[22] European Commission, European Opinion Research Group, "Special Eurobarometer on Physical Activity", 183-6/Wave58.2-Physical activity, 2003 (Accessed April 26, 2020).

[23] DuBose KD, Edwards S, Ainsworth BE, Reis JP, Slattery ML, "Validation of a historical physical activity questionnaire in middle-aged women", Journal of physical activity and health, vol. 4, no. 3, pp. 343-355, 2007. https://doi.org/10.1123/jpah.4.3.343.

[24] Adeniyi WO, Onadiji O. "Influence of Psycho-Demographic Variables on Psychological Well-Being of Undergraduates of Obafemi Awolowo University, Ile-Ife, Osun State", European Scientific Journal, vol. 12, no. 13, pp. 1857 - 7881, 2016. doi: 10.19044/esj.2016.v12n13p82 URL:http://dx.doi .org/10.19044/esj.2016.v12n13p82.

[25] Khumalo I, Temane QM, Wissing MP, "Socio-Demographic Variables, General Psychological Well-Being and the Mental Health Continuum in an African Context", Social Indicators Research, vol. 105, no. 3, pp. 419-442, 2012. https://doi.org/10.1007/s11205-010-9777-2.

[26] Adegoke BOA, Oyeyemi, AL, "Physical Inactivity in Nigerian Young Adults: Prevalence and Socio-Demographic Correlates", Journal of Physical Activity and Health, 2011, vol. 8, no. 8, pp. 1135 -1142. doi:10.1123/jpah.8.8.1135.

[27] Eime RM, Harvey JT, Charity MJ, Rayoni N, "Demographic characteristics and type/frequency of physical activity participation in a large sample of 21,603 Australian people", BMC Public Health, vol. 18 no. 692, 2018. https://doi.org/10.1186/s12889-018-5608-1

[28] Nestor A. "Socio-demographic determinants of physical activity (PA): A working class perspective" Cogent Medicine, vol. 3: 1276037, 2016. http://dx.doi.org/10.1080/ 2331205X.2016.1276037 